\title{
The research of relationship between college English listening and learning styles
}

\author{
Chunmiao Huang \\ Guangxi University Xingjian College of Science and Liberal Arts \\ Nanning,Guangxi,530005 China
}

\begin{abstract}
The relationship between college English listening and learning style suggests: listening scores showed strong field-independent learning style, and poor academic performance showed hybrid learning styles without actual meanings, especially independent type learning styles means a lot for college English listening learning; in the process of English listening teaching, students with good academic performance showed a field-independent learning style for reasons, and with strong self-learning ability, although students with poor performance will conducive to hybrid learning styles of language learning, but lacking of selflearning ability, academic performance is not satisfactory, then the students' academic performance depend on self-learning ability. The report also indicates two results, questions raised that overall performance of students in the field of a strong independent learning style (top) and good listening scores show appearances independent learning styles which are non-ideal in realty of the most of the students' ability
\end{abstract}

Keywords- learning styles; hearing results; field independence; Field dependence; independent learning

\section{COMMON LEARNING STYLES IN ENGLISH STUDYING}

\section{A. The perception angle from vision and audition}

Language learning which functions together with vision as well as audition, but to some extent the reality is separated. Visual learners showed great interests on the obvious visual effect, and with strong memory. They get used to by means of pictures, videos, performances and other visual stimuli to carry out study; they also prefer reading rather than speaking loudly. Auditory learners are more inclined to learn sound material. They are happy to communicate in English, showing greater enthusiasm on tape recordings and other training, and they can retell audio file easily and also flexibly in verbal expressing.

\section{B. Group cooperation style and individual researching style}

Group cooperation refers to the spontaneous formation of the corresponding study group in English learning; internal team members are closely related, good communication and mutual exchange of views on the issue of multi-expression argument, mutual help and supervision in order to achieve the common goal of a clear division of labor and task execution. Individual researching type refers to the learner with a strong learning autonomy, a strong sense of independence, but they are not good at communicating and are accustomed to solving problems through personal power.

\section{Active type and profound thinking type}

Learners personality affects learning styles, lively learners showed more enthusiasm for learning, responsive, high degree of enthusiasm for learning, and it is usually carried out directly through an intuitive analysis of external conditions and views expressed, they seem not to be calm enough caused by a thoughtless idea. Deep thinking type of learners in solving problems will be thoughtful, careful analysis, tradeoff.

\section{Detailed planning style and general understanding style}

Detailed planning Learners have detailed plans in learning at each stage and learning progress with their own standards. They pay attention to detail control, information processing in the study have a strong logic, good will collate information classification, the problem for the decentralized processing, and then separately. General understanding learners make macro grasp and control on content. Studying order, learning progress and learning arrangements and adjustments will be decided since a complete control of the learning requirements according to their characteristics, less care about the details of the learning, and to achieve the effect of the learning task ultimately

\section{THE CONNOTATION AND MEASUREMENTS OF THE COLLEGE STUDENTS' LEARNING}

Scholars study on students' learing problems, and learning style is an important concept they universally care about, but people have not reached agreement on this understanding. Cognitive researchers concerned with the perception of cognitive function. Researchers focus on personalities will discuss learning styles from personality instead of cognitive perspectives. Researchers center on learning activities stress the importance of the role of student perception of teaching situations, motivation orientation and processing methods. We believe that learning styles of learners have learning tendencies outlooks which should be relatively consistent, long-lasting, it is also a complex of learning orientation, a complex cognitive processing strategies and management strategies posed, it reflects a 
consistent manner when learner deal with the information to the situations, and it will maintain steady in a given period.

\section{OFFER DIFFERENT TEACHING STRATEGIES ON DIFFERENT LEARNING STYLES}

For visual learners, it is necessary to use illustrations material as much as possible, photos, videos and movies, and other great visual impact of viewing objects can fully mobilize the interest of their learning. For auditory learners, their learning arrangements such as verbal explanations, listening training and class discussion these should be better done in terms of verbalization Research for the individual learner, the teacher should actively encourage students to participate in collective learning activities in exchange of views with others, and organize some learning activities to show their expertise. For group cooperation learners, teachers should give full play to its advantages in communication; arrange performed skits, panel discussions, group competitions and many other activities to show the individual strengths of a team. For active learners, they are required to be more careful in the learning task, the teacher should be more patient in counseling; for deep thinking type of learners, teachers should encourage them to speak confidently and express their views in a timely manner; for well- planned learning learners, teachers give more learning tasks that need to be deeply analyzed; for general understanding learners, teachers need to actively mobilize them to make students involved in the classroom as much as possible.

Students can use learning strategies actively although their English level is generally low. Met cognitive and compensation strategies used most as emotional social strategies used less; eugenics more effectively use met cognitive strategies than poor students. Therefore teachers need to ask students to reflect customarily to make clear to the individual learning strategies which can be clearly identified, enhance the experience and regulation to choose the specific language learning environment and tasks strategies based on the characteristics of the different stages of learning in the teaching process, and from single policy development integrated use into a variety of strategies to achieve the purpose of improving the quality of learning. The diversity of student learning styles differ, teachers should take individual differences in different teaching styles and strategies to adapt to learners, students adjust and extend their learning styles and strategies to adapt to different styles of teachers. Teacher-student interaction makes them fit each other in order to achieve the desired results.

The main perceptual learning style preferences of are separate type and auditory. Secondary learning style preferences are visual type and group type. Perceptual learning styles of freshmen and relates to English proficiency; there are significant differences between the visual type and individual learning styles on students' test scores. The results tell us that if students are able to realize their own advantages and disadvantages of learning styles, which will help them to make good use of learning styles with some relevance in the study to improve learning efficiency, but it also helps poor students be aware of where their strengths and weaknesses lie in learning style, to find a suitable way to generate interest and confidence in learning. At the same time, understanding the students' learning styles is also to help college English teachers adjust teaching appropriately, providing opportunities to develop their potential and expertise of the different learning styles of students.

Learning style was first used by American scholar Hubert - Salem (Herbert Thelon) proposed in 1954, as what the learning style is, it has failed to form a unified definition so far. Many Western scholars from their point interpreted the connotation of learning styles: Guilford said: learning style refers to the preference of individual ability when he is handling different types of information. Dunn (Dunn), Cave et al. (1979): Learning style is student learning orientation or preference, it indicates that a particular student in the teaching process usually prefer to adopt ways of learning. In China, more generally accepted definition is Mr. Tan Dingliang's learning style: Learning style is a consistent approach to learner with personality characteristics, is the summation of the learning strategies and learning tendencies . Learning strategy is a series of steps for learners to complete the tasks or to achieve goals, and one procedure is a particular learning method. Learning tendency means different preferences for each individual in the learning process including learning, such as emotional, attitude, motivation, persistence and the preferences to learning environment, learning content preference. Some learning strategies and learning tends are to change with the environment and the content of learning, while others showed persistence. Learning strategies and learning tendencies those are to continue to consistently manifested, named learning style. The learning styles of learners commonly used. Once some kind of learning styles formed, it will be relatively stable. To some extent, students' learning style is a concentrated expression of individual differences. Foreign scholars do a lot of deep researches in studying the relationship between style and academic achievement. The results show that learning style is closely associated with academic achievement; successful learning is the result of adaption in teaching styles and learning styles.

\section{A CLOSE RELATIONSHIP BETWEEN COLLEGE} STUDENTS' LEARNING STYLES AND ACADEMIC ACHIEVEMENT

Different tendencies lead to different results. Active type students are inferior to the contemplative type on performance. From characteristics of the active type, they are open-minded and passionate about new things, but often act on intuition; to handle processing of information directly, they did not make a careful analysis of the problem just based on a part of information, to make a decision quickly and eager to give answers. In the classroom, they actively speaking and dare to express their views, but they are not skilled at comprehensive consideration for a variety of possibilities to the problem, poor accuracy when answering. These students usually less focus on inter-bottom of the problem, so the results will be worse, contemplative type of student performed cautiously. In class discussions, they usually format their own points after listening to the views of others' and react thoughtfully, they can analyze the problem 
from different angles, and all possible problems will be taken into account before the action., generally, a conclusion is to be accurate once made, so better at complex learning and test scores should be better. Because of sentiment-based learning students are not good at discovering the links between things due to that they prefer the facts but not complicated situations, and Intuitive students like joining in abstract and future-oriented activities, tend to find some kinds of possibility and the relationship between things, so the results are better than intuitive perception types'. In college students, the visual type students, their academic performance is also significantly higher than the verbal type learners'. This may be due to receive more vivid through visual materials, and easily remembered. Visual learners like to read silently, remember something they saw indeed, such as text, diagrams, flow charts, images, videos, etc. These students may not pay attention to teachers' explanations. The verbal learners prefer to listen rather to read, it is a good way for them to get information by listening, such as listening to the teacher's explanation. They can concentrate on school attendance, but can not concentrate on while reading. Each student will be able to get more information if you simultaneously get information through visual and auditory. With regard to the information understanding, the survey showed that those students are more than a sequence type integrated, and add the results are higher than under the integrated sequence of results. This is because the sequence type of students to solve problems follow logical rules step by step, so that you can clearly know each part of learning content, and integrated student learning material to arbitrarily absorb any material without link and then suddenly get a sense, they, do not know the details only have a general understanding of the material.

It is the tendency of different learning styles of individual differences in students' performance. Students learn in terms of different ways, or pay attention to the visual impression of auditory responses or preferences, or thinking or practice, which is directly reflected in the different learning methods, will eventually make academic performance good or not. Teaching methods differ, lectures, presentation, discussion and emphasis on rules, or focusing instance, or emphasize memory, or focus on understanding, students acquire much knowledge in the classroom, on one hand, their performance depends on own ability and lesson preparation, on the other hand, it depends on the use of learning methods, and teaching methods are coordinated. Therefore, after understanding the impact of learning styles on academic achievement, teachers should help students to analyze not only in the style but also consciously help students identify their own learning styles, cultures that they can consciously change for different learning tasks and adjust their learning style capabilities. More importantly, teachers should learn styles for students to actively explore, adjust the teaching mode, take a wide range of teaching methods, means and strategies to adapt and expand the student's learning style, truly individualized, thereby improving the quality of teaching

\section{CONCLUSIONS}

Foreign language learning is a bilateral activity between teachers and students. They need to cooperate with each other, and based on mutual adjustment and mutual adaptation, teachers should make teaching styles matched with students learning styles. In particular, lesson taught by second grade teachers, students should be given personal involvement, experiential learning activities in the classroom and opportunities to "do" school, thus enhancing their enthusiasm for learning. Meanwhile, teachers divide the same learning styles students into different groups to complement each other during group activities. Thus, teachers should adopt comprehensive English teaching methods, focusing on the output of information from different sources in order to meet the needs of learners to improve teaching effectiveness.

\section{ACKNOWLEDGEMENT}

Subject Name: Preference of English learning styles of minority undergraduate in Guangxi University

Project number: 2013C216

\section{Reference}

[1] Li Jie. Research learning styles and learning strategies and academic achievement of related research in English [J] Beijing International Studies University, 2011, 04: 72-78 + 83 .

[2] Lu Genshu, Correlation analysis book learning styles and academic achievement [J] Higher Engineering Education Research, 2005, 04: 44-48.

[3] Huang Ke. College Students' English learning styles and academic relations [D]. Shaanxi Normal University, 2005.

[4] Wang Lili, Independent College Students' English perceptual learning styles and academic-related investigation [J] China - ASEAN Expo, 2013, 11, 446.

[5] Tao Xingjuan, Cui Yan correlation between style and academic achievement $[\mathrm{J}]$ nursing students studying nursing magazines, 2007, $03,7-9$

[6] Guo Wei English learning styles research on English Achievement [J] Science and Technology Information, 2010, 24: 739-740. 